\title{
Insights From 10-Year Outcomes of Mesenchymal Stem Cell Transplantation in Heart Failure Patients
}

\author{
Oto Inoue, MD; Masayuki Takamura, MD, PhD
}

$\mathbf{T}$ he global incidence of chronic heart failure (CHF) is increasing, and it is a leading cause of death worldwide. ${ }^{1}$ Although medical and surgical therapies have progressed in recent decades, treatment of CHF patients with severe left ventricular (LV) dysfunction remains limited and the development of innovative methods is still needed.

Cell therapy using mesenchymal stem cells (MSCs) is a novel strategy to recover reduced ejection fraction $(\mathrm{EF})$ and improve the outcome in CHF patients. Preclinical studies have demonstrated favorable effects of MSC therapy on

\section{Article p 1590}

cardiac function in rodents. ${ }^{2}$ Since the mid- $2000 \mathrm{~s}$, clinical trials, including randomized controlled trials (RCTs), using bone marrow-derived MSCs (BMMSCs) have been conducted. ${ }^{3} \mathrm{~A}$ meta-analysis of cell therapy studies using bone marrow-derived cells, including BMMSCs (50 studies, 2,625 recipients) demonstrated that patients receiving cell therapy resulted in improvement of LV function with greater $\mathrm{EF}(+3.96 \%)$, reduced infarct size, and smaller $\mathrm{LV}$ volume. ${ }^{4}$

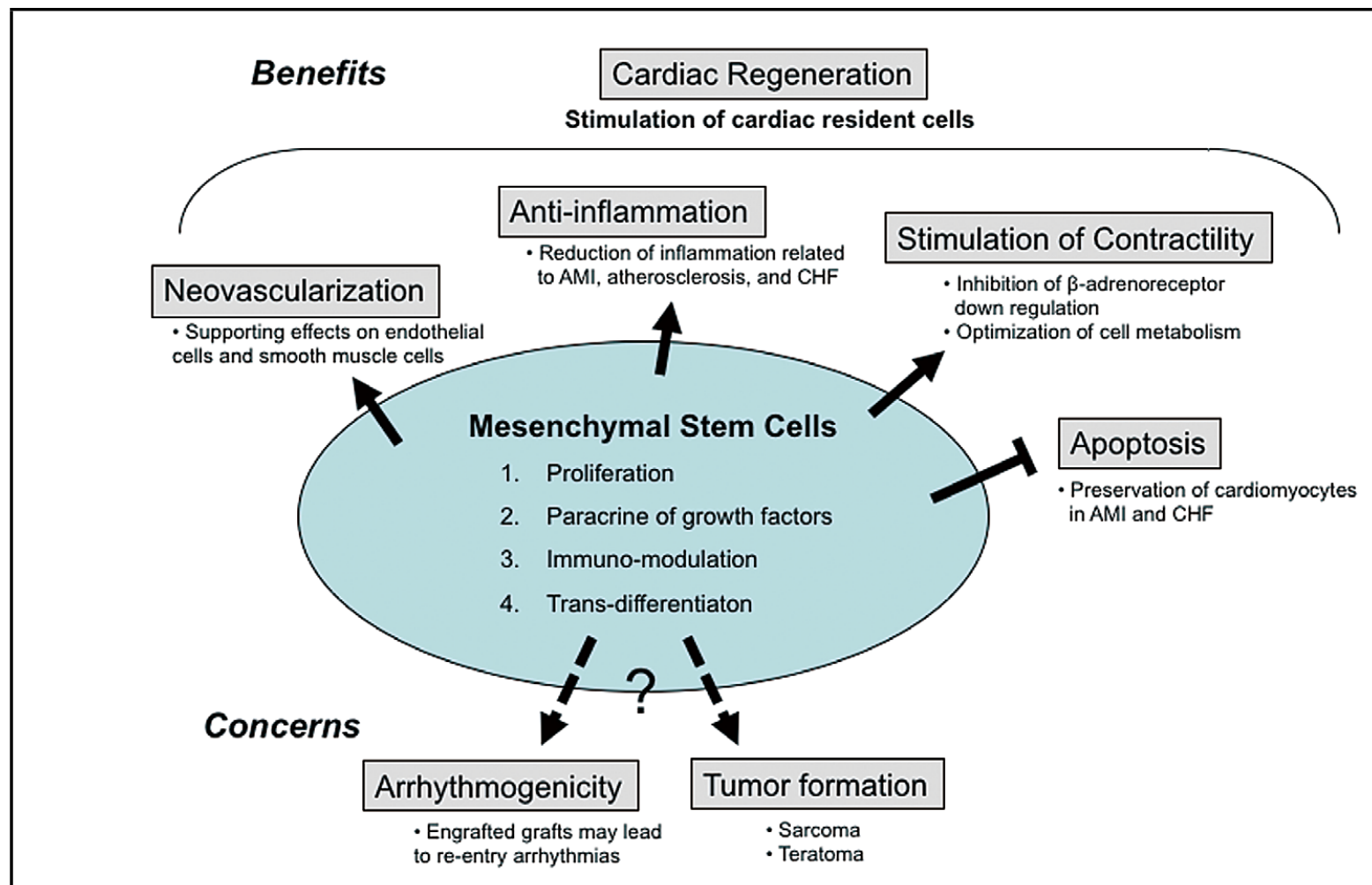

Figure. Graphical presentation of benefits and potential concerns associated with regenerative capacities of mesenchymal stem cells in heart failure. AMI, acute myocardial infarction; CHF, chronic heart failure.

The opinions expressed in this article are not necessarily those of the editors or of the Japanese Circulation Society.

Received May 7, 2019; accepted May 12, 2019; J-STAGE Advance Publication released online May 30, 2019

Department of Cardiology, Graduate School of Medical Science, Kanazawa University, Kanazawa, Japan

Mailing address: Oto Inoue, MD, Department of Cardiology, Graduate School of Medical Science, Kanazawa University, 13-1

Takara-machi, Kanazawa 920-8641, Japan. E-mail: oto0803inoue@gmail.com

ISSN-1346-9843 All rights are reserved to the Japanese Circulation Society. For permissions, please e-mail: cj@j-circ.or.jp 


\begin{tabular}{|c|c|c|c|}
\hline & \multicolumn{2}{|c|}{ Transplanted cell number } & \multirow{2}{*}{$P$ value } \\
\hline & Low group & High group & \\
\hline Patient no. & $2,4,8$ & $1,3,5,6$ & \\
\hline Cell number $\left(\times 10^{6}\right)$ & $12(12,18)$ & $56(51,60)$ & 0.04 \\
\hline Age (years) & $60(58,65)$ & $41(35,49)$ & 0.15 \\
\hline Male sex & 2 & 3 & 1.00 \\
\hline Etiology & & & 0.49 \\
\hline $\mathrm{DCM}$ & 1 & 3 & \\
\hline $\mathrm{ICM}$ & 2 & 1 & \\
\hline \multicolumn{4}{|c|}{$\begin{array}{l}\text { Change between baseline and } 2 \text { months after cell } \\
\text { transplantation }\end{array}$} \\
\hline $\mathrm{BNP}(\mathrm{pg} / \mathrm{mL})$ & $+5(-38,+104)$ & $-20(-35,-13)$ & 0.86 \\
\hline $\operatorname{LVEF}(\%)$ & $0(0,+1.5)$ & $+3(-0.5,+4.3)$ & 0.59 \\
\hline$\%$ PVC (\%) & $-0.1(-0.2,+0.4)$ & $-0.6(-0.6,+1.5)$ & 0.80 \\
\hline Peak $\dot{V O}_{2}(\mathrm{~mL} / \mathrm{min} / \mathrm{kg})$ & $+0.4(-0.1,+0.9)$ & $+1.6(-0.3,+3.7)$ & 0.53 \\
\hline \multicolumn{4}{|c|}{$\begin{array}{l}\text { Change between baseline and } 5 \text { years after cell } \\
\text { transplantation }\end{array}$} \\
\hline $\mathrm{BNP}(\mathrm{pg} / \mathrm{mL})^{*}$ & +152 (+116, +189) & $-35(-41,+46)$ & 0.40 \\
\hline $\operatorname{LVEF}(\%)^{*}$ & $-13(-16,-11)$ & $+2.0(+1.5,+5.5)$ & 0.20 \\
\hline NYHA class & & & 0.49 \\
\hline Improved & 0 & 0 & \\
\hline Unchanged & 1 & 3 & \\
\hline Worsen or died & 2 & 1 & \\
\hline
\end{tabular}

Numeric values are expressed as median and interquartile range (25th percentile, 75 th percentile). ${ }^{\text {Excludes patient }}$ no. 3 (heart transplantation) and patient no. 8 (died). BNP, B-type natriuretic peptide; DCM, dilated cardiomyopathy; ICM, ischemic cardiomyopathy; LVEF, left ventricular ejection fraction; NYHA, New York Heart Association; PVC, premature ventricular contraction; $\mathrm{V}_{2}$, oxygen uptake. (Reproduced with permission from reference 10.)

\section{Therapeutic Effects of MSCs on HF}

MSCs can be isolated from various sites of the body, including bone marrow, adipose tissue, umbilical cord blood, and dental pulp. MSCs have self-renewal potential and paracrine capacities of growth factors such as vascular endothelial growth factor (VEGF), hepatocyte growth factor (HGF), and fibroblast growth factor (FGF). ${ }^{\mathbf{5}, 6}$ Furthermore, under appropriate conditions, they can be transdifferentiated into cardiomyocytes (Figure). Paracrine effects are the major mechanism of action of MSCs on damaged cardiac resident cells, including endothelial cells, fibroblasts, and cardiomyocytes. Interestingly, MSCs are also reported to inhibit the downregulation of $\beta$-adrenoreceptor expression in a HF model. ${ }^{7}$ These favorable effects are assumed to synergistically contribute to improved cardiac function.

\section{Safety of BMMSC Therapy for HF}

Intramyocardial injection of MSCs raises some concerns about arrhythmogenicity and tumor formation, regardless of whether the injected MSCs engraft and transdifferentiate into cardiomyocytes. To treat CHF, skeletal myoblasts were first used around the year 2000. In the MAGIC (Myoblast Autologous Grafting in Ischemic Cardiomyopathy) study, the first multicenter, double blind, RCT of myoblast transplantation in patients with LV dysfunction, arrhythmic events of refractory ventricular tachycardia were reported, although LV volumes were significantly decreased in the treatment group. ${ }^{8}$ In contrast, recent trials have shown that BMMSC transplantation did not increase fatal arrhythmias. ${ }^{4}$

Tumor formation is also a major and possible complica- tion of BMMSC therapy because heart and ectopic tumor formation has been reported in experimental studies. ${ }^{9}$ Fortunately, there is no evidence to date of malignant tumor formation associated with BMMSC transplantation. However, follow-up periods of almost all of the reported studies were up to a maximum of 3 years. Compared with other complications, including hemorrhage, infection and arrhythmia, tumor formation potentially occurs in the later phase after cell therapy. Therefore, a longer survey for tumor formation is required to confirm the safety of MSC therapy. In this issue of the Journal, Yagyu et al ${ }^{10}$ report their 10-year outcomes of BMMSC therapy via intramyocardial injection for symptomatic CHF patients ( $\mathrm{EF}<40 \%$, ischemic and non-ischemic). No major adverse events, such as fatal arrhythmia and malignant tumors directly caused by BMMSCs injection, were observed during the follow-up period (median: 8.7 years). Although sample size was relatively small $(n=8)$, this is valuable information for researchers and clinicians involved in cell therapy.

\section{Efficacy of BMMSC Therapy for HF}

Importantly, Yagyu et al also investigated the efficacy of cell therapy, particularly the relationship between the changes in EF from baseline values and the number of injected BMMSCs (Table). In this analysis, patients received

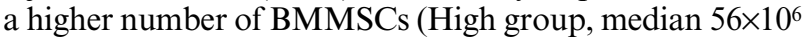
cells), demonstrating $+3 \%$ EF at 5 years after cell therapy. Although this is statistically insignificant because of the small sample size, patients receiving a lower number of BMMSCs (Low group, median $12 \times 10^{6}$ cells) showed progression of $\mathrm{LV}$ dysfunction with decreased $\mathrm{EF}$ by $-13 \%$ from baseline. Moreover, the High cell number group also 
showed a reduced B-type natriuretic peptide level relative to baseline (High group vs. Low group, $-35 \mathrm{vs} .+152 \mathrm{pg} / \mathrm{mL}$ ). Consistently, in the CCTRN TIME (Cardiovascular Cell Therapy Research Network Timing in Myocardial Infarction Evaluation) trial, administration of a higher percentage of $\mathrm{CD} 45^{+} \mathrm{CD} 31^{\text {low }}$ bone marrow-derived single cells resulted in significantly reduced infarct size at 6 months after cell therapy. ${ }^{11}$ Recently, several studies have reported that repeated injections of bone marrow-derived cells significantly improve LV function and long-term survival.12,13 These data give insights into the improvement of BMMSC therapy, because cell therapy might exhibit dose-dependent efficacy.

In summary, the safety and feasibility of BMMSC therapy for $\mathrm{CHF}$ patients has become widely recognized. The 10 -year outcomes reported by Yagyu et al provide valuable information regarding long-term safety. ${ }^{10}$ The efficacy of current BMMSC therapy is favorable, but still modest. ${ }^{4}$ High-dose or repeated injections of BMMSCs might greatly improve the efficacy of cell therapy. Further investigations and technical/methodological improvements, as well as a well-designed clinical trial, could affirm the clinical application of MSC therapy for CHF treatment.

\section{Conflict of Interest}

The authors report no relationships that could be construed as a conflict of interest.

\section{References}

1. Roth GA, Johnson C, Abajobir A, Abd-Allah F, Abera SF, Abyu G, et al. Global, regional, and national burden of cardiovascular diseases for 10 causes, 1990 to 2015. J Am Coll Cardiol 2017; 70: $1-25$.

2. Bodine DM, Leri A, Chimenti S, Anversa P, Kajstura J, Orlic D. Bone marrow stem cells regenerate infarcted myocardium.
Nature 2003; 410: 701-705.

3. Observer C, Alto P, Program T, Hospital M. Bone marrow therapies for chronic heart disease. Stem Cells 2015; 33: 3212 3227.

4. Jeevanantham V, Butler M, Saad A, Abdel-Latif A, Zuba-Surma EK, Dawn B. Adult bone marrow cell therapy improves survival and induces long-term improvement in cardiac parameters. Circulation 2012; 126: 551-568.

5. Gnecchi M, Zhang Z, Ni A, Dzau VJ. Paracrine mechanisms in adult stem cell signaling and therapy. Circ Res 2008; 103: 12041219.

6. Takashima SI, Tempel D, Duckers HJ. Current outlook of cardiac stem cell therapy towards a clinical application. Heart 2013; 99: $1772-1784$.

7. Dhein S, Garbade J, Rouabah D, Abraham G, Ungemach FR, Schneider K, et al. Effects of autologous bone marrow stem cell transplantation on beta-adrenoceptor density and electrical activation pattern in a rabbit model of non-ischemic heart failure. $J$ Cardiothorac Surg 2006; 1: 1-11.

8. Menasché P, Alfieri O, Janssens S, McKenna W, Reichenspurner $\mathrm{H}$, Trinquart L, et al. The Myoblast Autologous Grafting in Ischemic Cardiomyopathy (MAGIC) Trial. Circulation 2008; 117: $1189-1200$.

9. Miura M, Miura Y, Padilla-Nash HM, Molinolo AA, Fu B, Patel V, et al. Accumulated chromosomal instability in murine bone marrow mesenchymal stem cells leads to malignant transformation. Stem Cells 2005; 24: 1095-1103.

10. Yagyu T, Yasuda S, Nagaya N, Doi K, Nakatani T, Satomi K, et al. Long-term results of intracardiac mesenchymal stem cell transplantation in patients with cardiomyopathy. Circ J 2019; 83: $1590-1599$.

11. Schutt RC, Trachtenberg B, Cooke JP, Traverse JH, Henry TD, Pepine CJ, et al. Bone marrow characteristics associated with changes in infarct size after STEMI: A biorepository evaluation from the CCTRN TIME Trial. Circ Res 2015; 116: 99-107.

12. Assmus B, Alakmeh S, De Rosa S, Bonig H, Hermann E, Levy $\mathrm{WC}$, et al. Improved outcome with repeated intracoronary injection of bone marrow-derived cells within a registry: Rationale for the randomized outcome trial REPEAT. Eur Heart $J$ 2016; 37: $1659-1666$.

13. Vrtovec B, Bolli R. Potential strategies for clinical translation of repeated cell therapy. Circ Res 2019; 124: 690-692. 